\title{
Prevalence and Impact of Comorbid Widespread Pain in Adults with Chronic Low Back Pain: A Registry-Based Study
}

\author{
John C. Licciardone, DO, MS, MBA and Vishruti Pandya, MBBS, MHA
}

Introduction: Widespread pain (WP) is emerging as a key comorbid condition in patients with chronic low back pain (CLBP). This study measured the prevalence of comorbid WP in adults with CLBP, WP predictors, and impact on patients.

Metbods: Patients with CLBP were recruited from the Pain Registry for Epidemiologic, Clinical, and Interventional Studies and Innovation from 2016 through 2019. They were followed over 12 months to measure annual WP period prevalence rates using an item from the minimum dataset recommended by the National Institutes of Health Task Force on Research Standards for Chronic Low Back Pain. Patients were classified as not having WP, having nonpersistent WP, or having persistent WP. Pain intensity, back-related disability, and quality of life were measured using a numerical rating scale, the RolandMorris Disability Questionnaire, and the PROMIS-29 instrument, respectively.

Results: A total of 358 patients were studied, including 56 (16\%) without WP, 272 (76\%) with nonpersistent WP, and $30(8 \%)$ with persistent WP. There were no significant differences among the WP groups with regard to age, sex, or CLBP duration. However, being non-White and having moderate or high levels of pain catastrophizing remained significant predictors of nonpersistent or persistent WP after adjusting for potential confounders. Patients reported greater pain intensity and back-related disability and poorer quality of life over 12 months with increasing levels of WP persistence $(P<.001$ for each measure).

Conclusion: Greater efforts are needed in primary care to help close these gaps in pain intensity, back-related disability, and quality-of-life outcomes associated with WP. ( J Am Board Fam Med 2020;33:541-548.)

Keywords: Catastrophization, Comorbidity, Low Back Pain, Prevalence, Primary Health Care, Quality of Life, Registries

\section{Introduction}

Low back pain is a pervasive condition that affects over 600 million persons worldwide and is the leading cause of disability. ${ }^{1}$ In the United States, about 50 million adults suffer from chronic pain. ${ }^{2}$ This includes about 20 million adults with high-impact

This article was externally peer reviewed.

Submitted 18 December 2019; revised 14 February 2020; accepted 19 February 2020.

From the Department of Family Medicine, University of North Texas Health Science Center, Fort Worth, TX (JCL, VP)

Funding: No funding was provided for this study.

Conflicts of interest: None declared.

Corresponding author: John C. Licciardone, DO, MS, MBA, University of North Texas Health Science Center, Department of Family Medicine, 3500 Camp Bowie Boulevard, Fort Worth, TX 76107 (E-mail: john. licciardone@unthsc.edu). chronic pain, such as low back pain that interferes with work or life most days or every day. Although primary care physicians often face challenges in treating patients with low back pain that has become chronic and potentially disabling, the extent of this burden has not been well established. The National Pain Strategy called for more precise prevalence estimates of high-impact chronic pain to help develop and implement appropriate pain interventions. ${ }^{3}$ The National Institutes of Health Task Force on Research Standards for Chronic Low Back Pain (NIH-RTF) recommended assessing pain impact based on pain intensity, functional status, and quality of life, and considering widespread pain (WP) a key comorbid condition. ${ }^{4}$ Chronic low back pain (CLBP) may progress to $\mathrm{WP}$, with fibromyalgia manifesting as an extreme form of the 
condition. Fibromyalgia was originally associated with 11 or more tender point sites identified by clinical examination. ${ }^{5}$ However, updated fibromyalgia criteria and self-report scales have been developed to enable epidemiologic research in the absence of clinical examination. ${ }^{6,7}$ The objectives of this study were to: measure annual period prevalence rates of nonpersistent and persistent WP among patients with CLBP using a simple patient self-report item; to identify WP predictors; and to assess the impact of WP on low back pain intensity, functional status, and quality of life.

\section{Methods}

Patients for this historical cohort study were selected from the Pain Registry for Epidemiologic, Clinical, and Interventional Studies and Innovation (PRECISION Pain Research Registry) within Texas from April 2016 through January 2019. A registry overview has been published. ${ }^{8}$ Registry patients were recruited using clinic advertisements, communications with health care providers, newspaper advertisements, and social media to direct potential participants to the online screening site. Registry eligibility criteria included 1) being 21 to 79 years of age, 2) having English-language proficiency, and 3) having subacute low back pain or CLBP. However, the present study included only patients who met the NIHRTF case definition for CLBP. ${ }^{4}$ The latter required patients to report low back pain duration of at least 3 to 6 months, with a corresponding pain frequency of at least half of the days during the past 6 months. Registry patients are currently required to have a physician for their low back pain, as no diagnostic testing or treatment is provided by the registry. Study patients were required to attend the baseline registry encounter in person; however, follow-up encounters may have been completed in person, telephonically, or online. Regardless of the manner in which encounters were completed, all data were self-reported by patients and entered using electronic case report forms that precluded missing item responses. Thus, missing data were attributable only to missed encounters or registry attrition. Enrolled patients with complete data at each subsequent quarterly encounter over 12 months were included in the study. Pregnant or institutionalized patients were excluded. The North Texas Regional Institutional Review Board approved the study.
Figure 1. Flow of patients through the study.

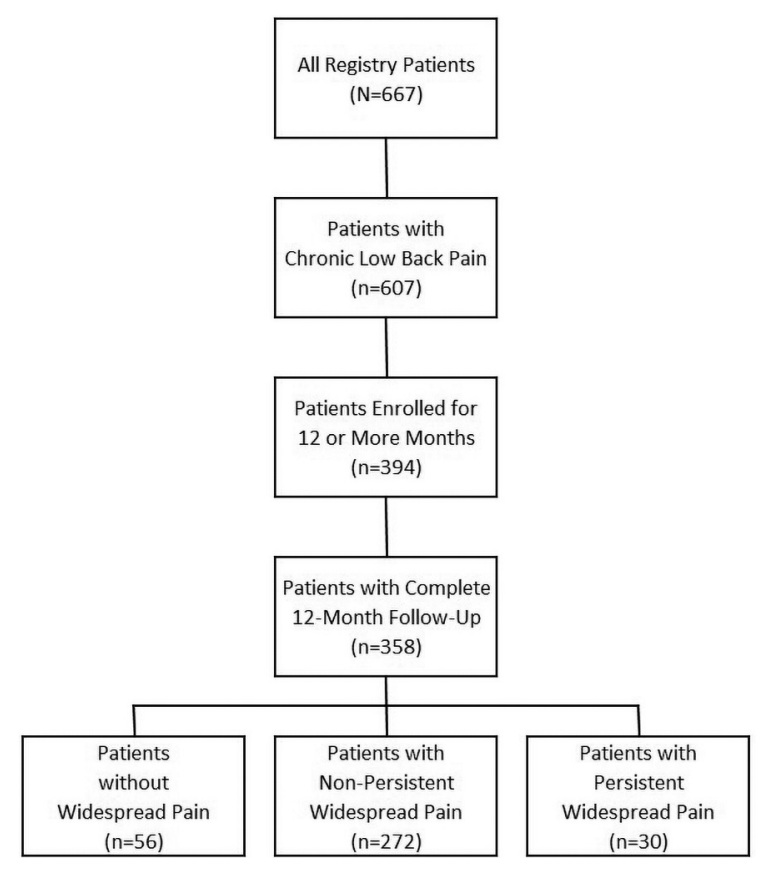

The annual period prevalence of WP was assessed using the NIH-RTF minimum dataset item that measured the bothersomeness of "widespread pain or pain in most of your body" during the past 4 weeks ("not bothered at all," "bothered a little," or "bothered a lot") at each quarterly encounter. ${ }^{4}$ Patients who consistently reported being "not bothered at all" over 12 months were considered to not have WP. Patients who consistently reported being "bothered a lot" over 12 months were considered to have persistent WP. The remaining patients were considered to have nonpersistent WP.

Baseline clinical measures included the patientreported history of depression, Pain Catastrophizing Scale, ${ }^{9}$ Pain Self-Efficacy Questionnaire, ${ }^{10}$ numeric rating scale for low back pain intensity during the past 7 days, Roland-Morris Disability Questionnaire for back-related disability, ${ }^{11}$ and Patient-Reported Outomes Measurement Information System (PROMIS-29) ${ }^{12}$ Quality of life was measured using the SPADE cluster based on PROMIS-29 scales for sleep disturbance, pain interference with activities, anxiety, depression, and low energy/fatigue. The measures of low back pain intensity, back-related disability, and quality of life were repeated at quarterly intervals over 12 months. Contingency table methods and analysis of variance were used to 
Table 1. Baseline Sociodemographic, Clinical, and Psychological Characteristics of Patients ( $\mathrm{N}=358)$

\begin{tabular}{l} 
Characteristic \\
\hline Age, y \\
$21-49$ \\
$50-59$ \\
$60-79$ \\
Sex \\
Male \\
Female \\
Race \\
White \\
Non-White \\
Ethnicity \\
Non-Hispanic \\
Hispanic \\
Highest educational level \\
High school diploma or lower \\
Post-high school or some college \\
College degree or higher \\
Cigarette smoking status \\
Never or former smoker \\
Current smoker \\
Chronic low back pain duration \\
Less or equal to 5 y \\
Greater than 5 y \\
History of low back surgery \\
No \\
Yes
\end{tabular}

Ever unemployed or unable to do usual work for one month or longer due to low back pain

No

Yes

Ever received disability or workers' compensation benefits relating to low back pain

No

Yes

Ever involved in a lawsuit or legal claim relating to low back pain

No

Yes

History of comorbidities

Herniated disc

No

Yes

Sciatica

No

Yes

Osteoarthritis

No

Yes
No. \%

11131

$128 \quad 36$

11933

$100 \quad 28$

$258 \quad 72$

$248 \quad 69$

$110 \quad 31$

$\begin{array}{ll}313 & 87\end{array}$

$45 \quad 13$

$91 \quad 25$

$142 \quad 40$

$125 \quad 35$

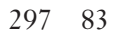

$61 \quad 17$

$128 \quad 36$

$230 \quad 64$

$301 \quad 84$

$57 \quad 16$

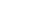

$224 \quad 63$

$134 \quad 37$

$273 \quad 76$

$85 \quad 24$

$321 \quad 90$

$37 \quad 10$

$232 \quad 65$

$126 \quad 35$

$241 \quad 67$

$117 \quad 33$

$242 \quad 68$

$116 \quad 32$

Continued

\section{Table 1. Continued}

\begin{tabular}{|c|c|c|}
\hline Characteristic & No. & $\%$ \\
\hline \multicolumn{3}{|l|}{ Osteoporosis } \\
\hline No & 319 & 89 \\
\hline Yes & 39 & 11 \\
\hline \multicolumn{3}{|l|}{ Heart disease } \\
\hline No & 321 & 90 \\
\hline Yes & 37 & 10 \\
\hline \multicolumn{3}{|l|}{ Hypertension } \\
\hline No & 218 & 61 \\
\hline Yes & 140 & 39 \\
\hline \multicolumn{3}{|l|}{ Diabetes } \\
\hline No & 283 & 79 \\
\hline Yes & 75 & 21 \\
\hline \multicolumn{3}{|l|}{ Asthma } \\
\hline No & 256 & 72 \\
\hline Yes & 102 & 28 \\
\hline \multicolumn{3}{|l|}{ Depression } \\
\hline No & 192 & 54 \\
\hline Yes & 166 & 46 \\
\hline \multicolumn{3}{|c|}{ Pain catastrophizing (PCS score) } \\
\hline Low $(0-8)$ & 112 & 31 \\
\hline Moderate (9-22) & 123 & 34 \\
\hline High (23-52) & 123 & 34 \\
\hline \multicolumn{3}{|c|}{ Pain self-efficacy (PSEQ score) } \\
\hline Low $(0-28)$ & 117 & 33 \\
\hline Moderate (29-42) & 116 & 32 \\
\hline High (43-60) & 125 & 35 \\
\hline \multicolumn{3}{|c|}{ Current use of opioids for low back pain } \\
\hline No & 227 & 63 \\
\hline Yes & 131 & 37 \\
\hline
\end{tabular}

Abbreviations: PCS, Pain Catastrophizing Scale; PSEQ, Pain Self-Efficacy Questionnaire.

compare WP groups at baseline. Multiple logistic regression was used to identify baseline factors associated with the presence of WP (either nonpersistent or persistent) over 12 months of follow-up. Predictor variables included patient sociodemographic characteristics, cigarette smoking status, CLBP duration greater than 5 years, history of low back surgery, history of 9 spinal or medical conditions, tercile levels of pain catastrophizing and pain self-efficacy (low, moderate, or high), and current use of opioids for low back pain. Repeated measures analysis of variance was used for longitudinal comparisons of the $3 \mathrm{WP}$ groups with regard to clinical measures involving low back pain intensity, backrelated disability, and quality of life. Statistical analyses were performed using the IBM SPSS Statistics software package (version 25, Armonk, NY). All 
Table 2. Factors Associated with Widespread Pain $(\mathrm{N}=358)$

\begin{tabular}{|c|c|c|c|c|c|c|}
\hline \multirow[b]{2}{*}{ Factor } & \multicolumn{3}{|c|}{ Univariate Analysis } & \multicolumn{3}{|c|}{ Multivariate Analysis } \\
\hline & OR & $95 \% \mathrm{CI}$ & $P$ & OR & $95 \% \mathrm{CI}$ & $P$ \\
\hline \multicolumn{7}{|l|}{ Age, $y$} \\
\hline $21-49$ & 1 & $\ldots$ & $\ldots$ & 1 & $\ldots$ & $\ldots$ \\
\hline $50-59$ & 1.6 & $0.8-3.3$ & .17 & 1.3 & $0.6-3.1$ & .49 \\
\hline $60-79$ & 1.2 & $0.6-2.4$ & .56 & 1.7 & $0.6-4.5$ & .30 \\
\hline \multicolumn{7}{|l|}{ Sex } \\
\hline Male & 1 & $\ldots$ & $\ldots$ & 1 & $\ldots$ & $\ldots$ \\
\hline Female & 1.2 & $0.6-2.1$ & .66 & 1.5 & $0.7-3.4$ & .34 \\
\hline \multicolumn{7}{|l|}{ Race } \\
\hline White & 1 & $\ldots$ & $\ldots$ & 1 & $\ldots$ & $\ldots$ \\
\hline Non-White & 3.6 & $1.6-8.3$ & .002 & 4.1 & $1.5-10.8$ & .01 \\
\hline \multicolumn{7}{|l|}{ Ethnicity } \\
\hline Non-Hispanic & 1 & $\ldots$ & $\ldots$ & 1 & $\ldots$ & $\ldots$ \\
\hline Hispanic & 1.2 & $0.5-3.1$ & .65 & 1.8 & $0.6-5.5$ & .29 \\
\hline \multicolumn{7}{|l|}{ Highest educational level } \\
\hline High school diploma or lower & 1 & $\ldots$ & $\ldots$ & 1 & $\ldots$ & $\ldots$ \\
\hline Post-high school or some college & 1.0 & $0.4-2.4$ & .92 & 1.8 & $0.6-5.2$ & .26 \\
\hline College degree or higher & 0.2 & $0.1-0.6$ & .001 & 0.6 & $0.2-1.8$ & .38 \\
\hline \multicolumn{7}{|l|}{ Cigarette smoking status } \\
\hline Never or former smoker & 1 & $\ldots$ & $\ldots$ & 1 & $\ldots$ & $\ldots$ \\
\hline Current smoker & 3.0 & $1.1-8.7$ & .04 & 1.3 & $0.4-4.5$ & .68 \\
\hline \multicolumn{7}{|l|}{ Chronic low back pain duration } \\
\hline Less than or equal to $5 \mathrm{y}$ & 1 & $\ldots$ & $\ldots$ & 1 & $\ldots$ & $\ldots$ \\
\hline Greater than $5 y$ & 1.6 & $0.9-2.8$ & .13 & 1.6 & $0.8-3.2$ & .19 \\
\hline \multicolumn{7}{|l|}{ History of low back surgery } \\
\hline No & 1 & $\ldots$ & $\ldots$ & 1 & $\ldots$ & $\ldots$ \\
\hline Yes & 1.2 & $0.5-2.6$ & .72 & 0.7 & $0.3-2.1$ & .58 \\
\hline \multicolumn{7}{|l|}{ History of comorbidities } \\
\hline \multicolumn{7}{|l|}{ Herniated disc } \\
\hline No & 1 & $\ldots$ & $\ldots$ & 1 & $\ldots$ & $\ldots$ \\
\hline Yes & 1.4 & $0.8-2.7$ & .26 & 1.2 & $0.5-2.7$ & .67 \\
\hline \multicolumn{7}{|l|}{ Sciatica } \\
\hline No & 1 & $\ldots$ & $\ldots$ & 1 & $\ldots$ & $\ldots$ \\
\hline Yes & 1.0 & $0.6-1.9$ & .93 & 0.9 & $0.4-1.9$ & .79 \\
\hline \multicolumn{7}{|l|}{ Osteoarthritis } \\
\hline No & 1 & $\ldots$ & $\ldots$ & 1 & $\ldots$ & $\ldots$ \\
\hline Yes & 1.4 & $0.7-2.6$ & .33 & 1.0 & $0.5-2.4$ & .92 \\
\hline \multicolumn{7}{|l|}{ Osteoporosis } \\
\hline No & 1 & $\ldots$ & $\ldots$ & 1 & $\ldots$ & $\ldots$ \\
\hline Yes & 1.3 & $0.5-3.5$ & 0.61 & 0.8 & $0.2-2.9$ & 0.77 \\
\hline \multicolumn{7}{|l|}{ Heart disease } \\
\hline No & 1 & $\ldots$ & $\ldots$ & 1 & $\ldots$ & $\ldots$ \\
\hline Yes & 1.2 & $0.5-3.3$ & .71 & 1.7 & $0.5-5.7$ & .40 \\
\hline \multicolumn{7}{|l|}{ Hypertension } \\
\hline No & 1 & $\ldots$ & $\ldots$ & 1 & $\ldots$ & $\ldots$ \\
\hline Yes & 1.3 & $0.7-2.4$ & .39 & 0.9 & $0.4-1.9$ & .70 \\
\hline \multicolumn{7}{|l|}{ Diabetes } \\
\hline No & 1 & $\ldots$ & $\ldots$ & 1 & $\ldots$ & $\ldots$ \\
\hline Yes & 2.5 & $1.0-6.0$ & .046 & 1.8 & $0.6-5.4$ & .28 \\
\hline
\end{tabular}

Continued 


\begin{tabular}{|c|c|c|c|c|c|c|}
\hline \multirow[b]{2}{*}{ Factor } & \multicolumn{3}{|c|}{ Univariate Analysis } & \multicolumn{3}{|c|}{ Multivariate Analysis } \\
\hline & OR & $95 \%$ CI & $P$ & OR & $95 \% \mathrm{CI}$ & $P$ \\
\hline \multicolumn{7}{|l|}{ Asthma } \\
\hline No & 1 & $\ldots$ & $\ldots$ & 1 & $\ldots$ & $\ldots$ \\
\hline Yes & 1.0 & $0.5-1.9$ & .99 & 0.6 & $0.3-1.3$ & .18 \\
\hline \multicolumn{7}{|l|}{ Depression } \\
\hline No & 1 & $\ldots$ & $\ldots$ & 1 & $\ldots$ & $\ldots$ \\
\hline Yes & 2.5 & $1.3-4.6$ & .004 & 0.8 & $0.4-2.0$ & .69 \\
\hline \multicolumn{7}{|c|}{ Pain catastrophizing (PCS score) } \\
\hline Low $(0-8)$ & 1 & $\ldots$ & $\ldots$ & 1 & $\ldots$ & $\ldots$ \\
\hline Moderate (9-22) & 4.3 & $2.2-8.7$ & $<.001$ & 4.7 & $2.1-11.0$ & $<.001$ \\
\hline High (23-52) & 12.1 & $4.6-32.2$ & $<.001$ & 6.8 & $2.1-22.1$ & .002 \\
\hline \multicolumn{7}{|c|}{ Pain self-efficacy (PSEQ score) } \\
\hline Low $(0-28)$ & 1 & $\ldots$ & $\ldots$ & 1 & $\ldots$ & $\ldots$ \\
\hline Moderate (29-42) & 0.4 & $0.2-1.0$ & .052 & 0.7 & $0.2-2.1$ & .55 \\
\hline High (43-60) & 0.2 & $0.1-0.4$ & $<.001$ & 0.7 & $0.2-2.2$ & .52 \\
\hline \multicolumn{7}{|c|}{ Currently using opioids for low back pain } \\
\hline No & 1 & $\ldots$ & $\ldots$ & 1 & $\ldots$ & $\ldots$ \\
\hline Yes & 3.5 & $1.7-7.5$ & .001 & 2.1 & $0.8-5.4$ & .12 \\
\hline
\end{tabular}

Results are for widespread pain (either non-persistent or persistent) relative to no widespread pain. Multivariate analysis included all univariate factors.

Abbreviations: PCS, Pain Catastrophizing Scale; PSEQ, Pain Self-Efficacy Questionnaire; OR, odds ratio; CI, confidence interval.

hypotheses were assessed at the 0.05 level of statistical significance using 2-sided tests.

\section{Results}

A total of $358(91 \%)$ of the 394 eligible patients completed the baseline encounter and each quarterly encounter over 12 months (Figure 1). There were $56(16 \%)$ patients who did not have WP, 272 (76\%) who had nonpersistent WP, and 30 (8\%) who had persistent WP. The mean age of patients was 53.6 years (SD, 12.2 years), 258 (72\%) were women, and 230 (64\%) had CLBP for more than 5 years (Table 1$)$. There were no significant differences among the $3 \mathrm{WP}$ groups with regard to age, sex, or CLBP duration. However, race and pain catastrophizing remained significant predictors of nonpersistent or persistent WP after adjusting for potential confounders (Table 2). Non-White patients were more likely than White patients to report WP (OR, 4.1; 95\% CI, 1.5 to $10.8 ; P=.01)$. This finding largely reflects the experience of Black patients, who comprised 97 (88\%) of the 110 nonWhite patients. Patients with moderate (OR, 4.7; 95\% CI, 2.1 to $11.0 ; P<.001)$ or high (OR, 6.8;
95\% CI, 2.1 to $22.1 ; P=.002)$ pain catastrophizing were more likely to report WP than patients with low levels of pain catastrophizing.

Patients reported greater low back pain intensity and back-related disability and poorer quality of life over 12 months with increasing levels of WP persistence $(P<.001$ for each measure) (Figure 2). A significant back-related disability $\times$ time interaction effect was also observed $(P=.01)$, wherein RolandMorris Disability Questionnaire scores declined over time in patients without WP, remained stable in patients with nonpersistent $\mathrm{WP}$, and increased in patients with persistent WP. All findings based on repeated measures analysis of variance remained essentially unchanged after controlling for age, sex, and CLBP duration.

\section{Discussion}

Nonpersistent or persistent WP was observed in $84 \%$ of patients with CLBP over 12 months of followup and was associated with adverse clinical consequences. These findings support the NIH-RTF stance that WP is a key comorbid condition in patients with CLBP, and suggest that WP may be 
Figure 2. Clinical measures over 12 months of followup according to widespread pain group. Abbreviations: NRS, numeric rating scale; RMDQ, Roland-Morris Disability Questionnaire; SPADE, sleep disturbance, pain interference with activities, anxiety, depression, and low energy/fatigue; WP, widespread pain. Greater scores represent worse status on each clinical measure. Error bars represent 95\% CI. $P$-values were computed using repeated measures analysis of variance. All WP groups were significantly different from one another in post-hoc comparisons for all clinical measures. A significant back-related disability $\mathbf{X}$ time interaction effect was also observed $(P=.01)$.

A

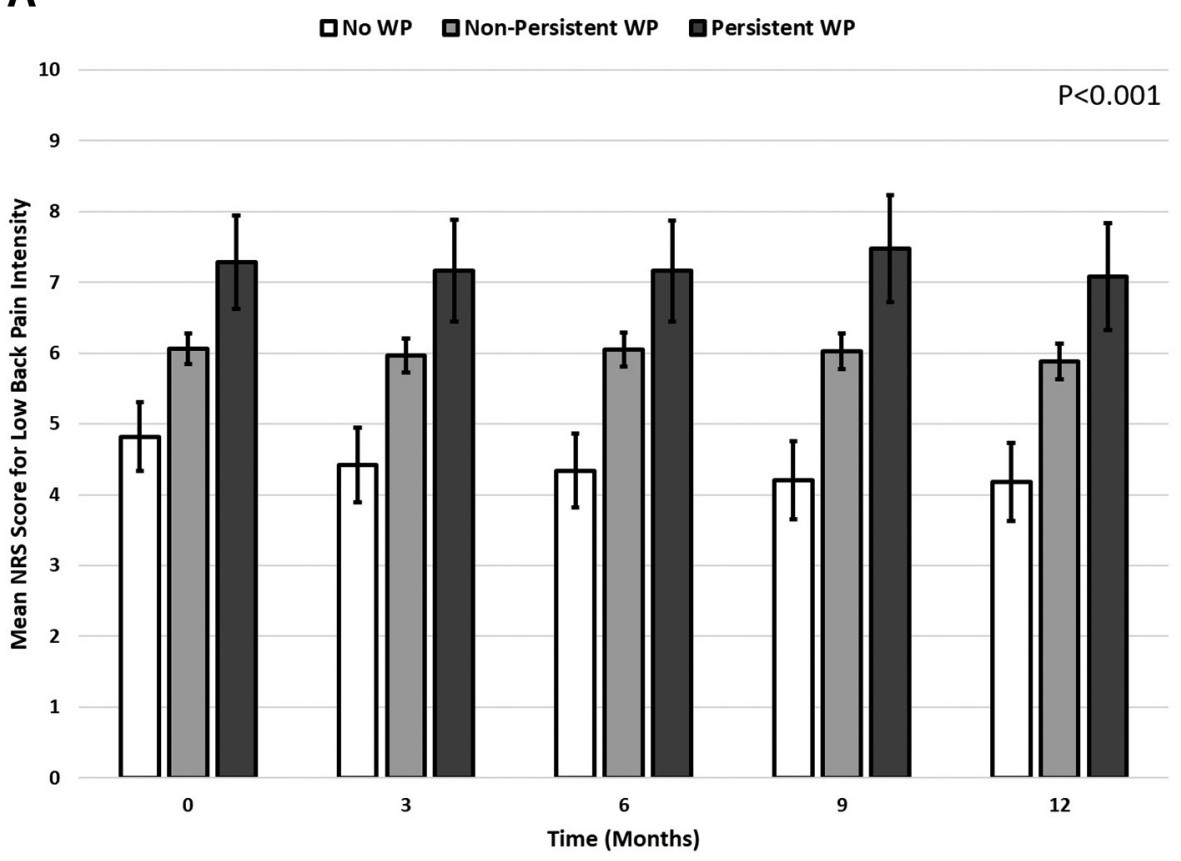

B

$\mathrm{P}<0.001$

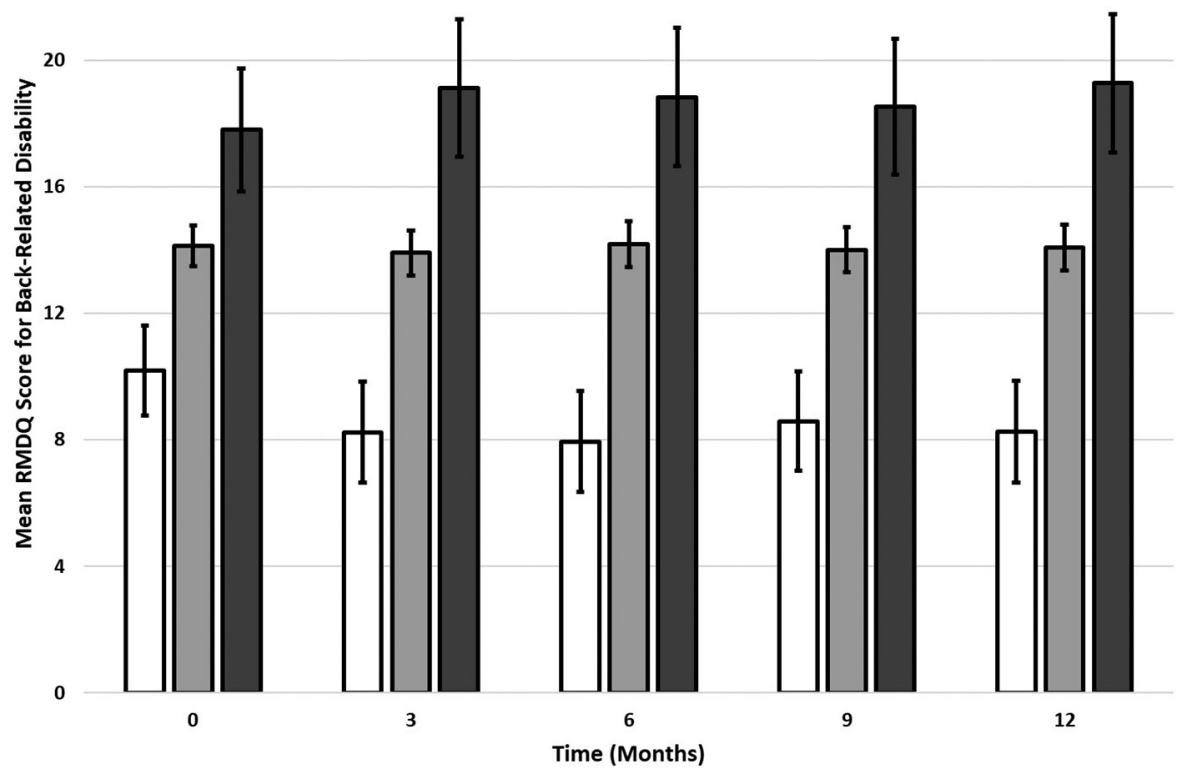


Figure 2. Continued

\section{C}

80

$\mathrm{P}<0.001$

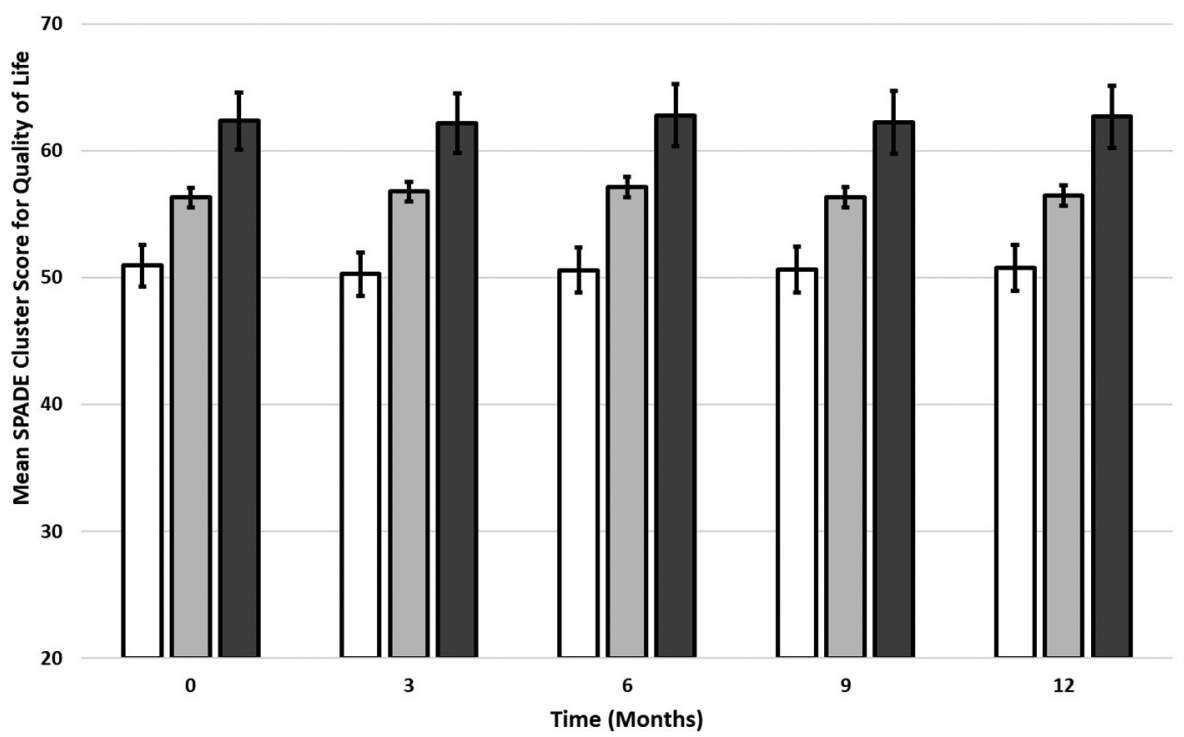

identified with a simple patient self-report item from the NIH-RTF minimum dataset. ${ }^{4}$ Epidemiologic studies involving large populations have reported prevalence rates of $5 \%$ to $14 \%$ for chronic WP and $1 \%$ to $3 \%$ for fibromyalgia. ${ }^{13}$ Among patients with CLBP, 25\% met the American College of Rheumatology criteria for chronic WP. ${ }^{14}$ Such patients with WP in the latter study were more likely to be female, have longer CLBP duration, and more often report comorbidities such as osteoarthritis and depression than patients without WP. The NIH-RTF item used in our study appears to identify patients at an earlier stage in the WP spectrum because significant associations with sex, CLBP duration, and medical comorbidities were not observed (Table 2).

The gradient in each clinical measure with increasing WP persistence generally remained constant over 12 months, despite ongoing active treatment for CLBP (Figure 2). A possible explanation for this phenomenon is that physicians may not routinely assess the presence and impact of WP when treating patients for localized pain. Consequently, pain management may not adequately address remote pain sites, physical functioning, and other quality-of-life issues relating to such factors as sleep disturbance, anxiety, and depression. However, simply providing a visual display of PROMIS symptom scores to primary care physicians in a busy clinical setting did not improve patient quality-of-life outcomes over 3 months. ${ }^{15}$ It remains to be seen if the simpler WP bothersomeness item from the NIH-RTF minimum dataset could be more efficiently and effectively implemented in clinical practice.

Limitations of our study include self-report measures and computation of WP period prevalence rates rather than incidence rates because there were too few patients who were WP-free at baseline to assemble a suitable prospective cohort. Nevertheless, disease registries such as ours may increasingly exploit the historic (ie, retrospective) cohort design to conduct pragmatic studies that assess health care outcomes in real-world settings. ${ }^{16}$ Low patient attrition was also a strength of our study.

In summary, annual period prevalence rates of $76 \%$ for nonpersistent WP and 8\% for persistent WP were observed in patients with CLBP using the NIH-RTF minimum dataset bothersomeness item. Being non-White and having moderate or high levels of pain catastrophizing were significant independent predictors of WP. Generally stable gradients involving greater low back pain intensity 
and back-related disability and poorer quality of life were observed over 12 months in patients with increasing levels of WP persistence. Greater efforts are needed in primary care to help close these gaps in clinical measures associated with WP.

To see this article online, please go to: bttp://jabfm.org/content/ 33/4/541.full.

\section{References}

1. Vos T, Flaxman AD, Naghavi M, et al. Years lived with disability (YLDs) for 1160 sequelae of 289 diseases and injuries 1990-2010: a systematic analysis for the Global Burden of Disease Study 2010. Lancet 2012;380:2163-96.

2. Dahlhamer J, Lucas J, Zelaya C, et al. Prevalence of chronic pain and high-impact chronic pain among adults-United States, 2016. MMWR Morb Mortal Wkly Rep 2018;67:1001-6.

3. Interagency Pain Research Coordinating Committee. National pain strategy: a comprehensive population health-level strategy for pain. Washington, DC: US Department of Health and Human Services, National Institutes of Health; 2016.

4. Deyo RA, Dworkin SF, Amtmann D, et al. Report of the NIH Task Force on Research Standards for Chronic Low Back Pain. J Pain 2014;15:569-85.

5. Wolfe F, Smythe HA, Yunus MB, et al. The American College of Rheumatology 1990 criteria for the classification of fibromyalgia. Report of the Multicenter Criteria Committee. Arthritis Rheum 1990;33:160-72.

6. Wolfe F, Clauw DJ, Fitzcharles MA, et al. Fibromyalgia criteria and severity scales for clinical and epidemiological studies: a modification of the ACR Preliminary Diagnostic Criteria for Fibromyalgia. J Rheumatol 2011;38:1113-22.
7. Wolfe F, Clauw DJ, Fitzcharles MA, et al. Revisions to the 2010/2011 fibromyalgia diagnostic criteria. Semin Arthritis Rheum 2016;46:319-29.

8. Licciardone JC, Gatchel RJ, Phillips N, Aryal S. The Pain Registry for Epidemiological, Clinical, and Interventional Studies and Innovation (PRECISION): registry overview and protocol for a propensity score-matched study of opioid prescribing in patients with low back pain. J Pain Res 2018; Volume 11:1751-60.

9. Sullivan MJ. The Pain Catastrophizing Scale: User Manual. Montreal, QC: McGill University; 2009.

10. Nicholas MK. The pain self-efficacy questionnaire: taking pain into account. Eur J Pain 2007;11:153-63.

11. Roland M, Morris R. A study of the natural history of back pain. Part I: development of a reliable and sensitive measure of disability in low-back pain. Spine 1983;8:141-4.

12. Intro to PROMIS. HealthMeasures. 2020. http:// www.healthmeasures.net/explore-measurementsystems/promis/intro-to-promis. Accessed February $10,2020$.

13. Staud R. Chronic widespread pain and fibromyalgia: two sides of the same coin? Curr Rheumatol Rep 2009;11:433-6.

14. Viniol A, Jegan N, Leonhardt C, et al. Differences between patients with chronic widespread pain and local chronic low back pain in primary care-A comparative cross-sectional analysis. BMC Musculoskel Disord 2013;14:351.

15. Kroenke K, Talib TL, Stump TE, et al. Incorporating PROMIS symptom measures into primary care practice: a randomized clinical trial. J Gen Intern Med 2018;33:1245-52.

16. Samet JM. Cohort study, historical. In: Gail MH, Benichou J, eds. Encyclopedia of Epidemiologic Methods. Chichester, UK: John Wiley \& Sons Ltd; 2000:215-7. 